\title{
Animalism and the Vagueness of Composition
}

\author{
Radim Bělohrad*
}

Received: 13 June 2018 / Accepted: 2 October 2018

Abstract: Lockean theories of personal identity maintain that we persist by virtue of psychological continuity, and most Lockeans say that we are material things coinciding with animals. Some animalists argue that if persons and animals coincide, they must have the same intrinsic properties, including thinking, and, as a result, there are 'too many thinkers' associated with each human being. Further, Lockeans have trouble explaining how animals and persons can be numerically different and have different persistence conditions. For these reasons, the idea of a person being numerically distinct but coincident with an animal is rejected and animalists conclude that we simply are animals. However, animalists face a similar problem when confronted with the vagueness of composition. Animals are entities with vague boundaries. According to the linguistic account of vagueness, the vagueness of a term consists in there being a number of candidates for the denotatum of the vague term. It seems to imply that where we see an animal, there are, in fact, a lot of distinct but overlapping entities with basically the same intrinsic properties, including thinking. As a result, the animalist must also posit 'too many thinkers' where we thought there was only one. This seems to imply that the animalist cannot accept the linguistic account of vagueness. In this paper the author argues that the animalist can accept the linguistic account of vagueness and retain her argument against Lockeanism.

* Masaryk University

- Department of Philosophy, Faculty of Arts, Masaryk University, Arna Nováka 1, 60200 Brno, Czech Republic

$\triangle$ belohrad@phil.muni.cz

() The Author. Journal compilation (C) The Editorial Board, Organon F.

This article is distributed under the terms of the Creative Commons Attribution-NonCommercial 4.0 International Public License (CC BY-NC 4.0). 
Keywords: Animalism; Lockeanism; partial identity; personal identity; supervaluations; vagueness.

\section{Introduction}

Animalism is a theory of personal identity according to which you and I are animals. A further claim that both some animalists and their opponents make is that animals persist by virtue of biological continuity. ${ }^{1}$ For an animal to exist, there has to be a life, and for an animal to continue existing, there has to be a continuing life (Olson 2007, 29; van Inwagen 1990, 145; DeGrazia 2005, 51-56).

There are other popular accounts of how we persist. Historically, the most influential have been psychological theories inspired by Locke, according to which we are not animals, but persons - essentially intelligent beings with sophisticated mental capacities, which persist by virtue of psychological continuity.

At first glance, there does not seem to be a disagreement between these two accounts. ${ }^{2}$ After all, could intelligent beings with sophisticated mental capacities not be animals? And could animals not be intelligent and have sophisticated mental capacities? In other words, could a particular animal

1 Not all animalists accept this claim. See, for instance, Snowdon (2014) for a theory according to which the criterion of personal persistence is the retention of the life-apt structure, or McDowell (1997) who defends the claim that psychological continuity is the criterion of persistence of animals. Also, as Olson (2015) points out, this claim is quite independent of the first claim. Olson coins the conjunction of the two claims strong animalism and concedes that it is strong animalism that usually stirs up debate. In what follows, when I refer to animalism, I always mean the conjunction of the two claims.

2 But, as Olson (2015) points out, the two accounts respond to very different questions. Animalism is a response to the question of what we are. Lockeanism responds to the question of how we persist. Neither answer has any direct implications for the other question. Olson also shows that the implications of Lockeanism for the 'What are we?' question are quite unclear. In this paper I accept the minimum that is usually accepted: persons are material entities with complex psychological properties, such as self-reflection, and, importantly, they are not animals. 
and a particular person not be one and the same thing? According to the Lockeans, they could not, because animals and persons differ in their essential properties and in what they can survive. While the persistence conditions of animals are biological, ours are psychological. This means that we persist as long as there is psychological continuity - an uninterrupted chain of mental states. ${ }^{3}$ If the chain is interrupted, we cease to exist, even though a living animal may continue to exist (Shoemaker 1984; Lewis 1976).

The claim that the lives of persons and animals may come apart is usually supported by thought experiments involving brain state transfer devices, teleporters, brain transplants, etc., or real-life examples of humans in a coma or a permanent vegetative state [see (Parfit 1984, 197-200), for instance].

There are a number of different psychological theories, but the most widely held ones claim that persons are material entities which are not animals, but are related to animals by a very intimate relation. In some versions this relation is material coincidence - the sharing of matter (Shoemaker 1984, 113). In others it is the relation of constitution (Baker 2000; Johnston 1987, 2007), though this also entails material coincidence (Baker 2000 , 43). Just as a statue is constituted by a lump of clay but is not identical to it, because the lump can persist through changes that the statue cannot, a person is (it is claimed) constituted by an animal but, for similar reasons, not identical to it.

Psychological theories of this sort must explain two mysteries.

\section{Mystery 1}

If persons are material entities, if each person is made of the same matter as an animal and if persons are not identical to animals, then where I am right now, there are two material entities - a person and an animal - that share every particle of matter and their overall structure. As a result, it

3 For instance, Parfit defines psychological continuity as the overlapping chains of strong psychological connectedness. Psychological connectedness is the holding of direct psychological connections, such as the connections between memories and the experiences that caused the memories, intentions and experiences of actions resulting from the intentions, etc. Connectedness is strong if "the number of connections, over any day, is at least half the number of direct connections that hold, over every day, in the lives of nearly every actual person' (Parfit 1984, 205). 
seems impossible to explain plausibly how these two entities could differ in the way that the Lockeans claim.

First, each such animal must be a person. Each such animal has a brain just like the person, the brain is functioning and, if consciousness and thought are generated by the functioning of the brain, each such animal is conscious and thinks. In fact, each such animal has mental capacities as complex as the coincident person. That seems to qualify it as a person, too (Olson 1997, 100). So if I am not an animal, as the Lockeans claim (that is, if I am a person and persons are not animals), there must be two conscious and thinking beings where we normally thought there was only one - me and the animal - which makes the Lockean theory inconsistent, because then there are two persons, only one of whom persists by virtue of psychological continuity (Olson 1997, 106-109). ${ }^{4}$

Second, each such person must be an animal. Being a material entity coincident with an animal, it must be composed of particles that together give rise to a life; it has a heart, lungs, metabolism, immune system, etc. In fact, it has all the characteristics that make the animal an animal. That seems to qualify it as an animal, too.

If an entity's intrinsic properties depend on its microphysical structure, it seems obvious that animals and persons must have the same intrinsic properties. That makes it a complete mystery how one can have biological persistence conditions while the other has psychological ones. How could something make one cease to exist while not affecting the other (Olson 1997, 98)? Call this the metaphysical mystery. ${ }^{5}$

\section{Mystery 2}

Suppose we can explain Mystery 1, and where I am there are two material entities that are indistinguishable in terms of their intrinsic properties. Which one of them am I? The question would not be worth answering if the alternative answers had no practical implications. But if I am an animal, I will still exist when in a permanent vegetative state (PVS), whereas if

4 This problem is often referred to as 'the thinking animal problem' or 'the too many thinkers problem'.

5 This is a special instance of the general problem of metaphysical grounding. See, for instance, (deRosset 2011). 
I am a person, I will not-no person can be identical to any being in PVS, because beings in PVS are not persons and all persons are persons essentially. Further, if I am a person, it may be rational for me to have my head removed at the moment of my death and preserved by Alcor in the hope of it being transplanted onto a new body one day-psychological continuity with the person in the new body will ensure it is me. If I am an animal, this would be an unjustifiable waste of resources, because the animal I am does not get transferred to the new body. ${ }^{6}$ But how am I to find out? I may think that I am the person, but the animal thinks the same. One of us is mistaken, though, and there is no way we can find out (Olson 1997, 106). Call this the epistemic mystery.

These two mysteries lead to the following argument against Lockeanism and in favour of animalism: if a particular animal and a particular person completely overlap and share every particle of matter, then they must be indistinguishable in their intrinsic properties. But if they are indistinguishable with respect to every intrinsic property and if we plausibly suppose that persistence conditions are grounded in intrinsic properties, then they cannot differ in their persistence conditions. But then what grounds do we have for claiming that the person is not the animal? If the person shares every intrinsic property with the animal and begins and ceases to exist at the same time as the animal, why suppose it is numerically distinct from the animal? The animal must be as conscious as the person is, the person must have a heart and breathe as much as the animal, and surely it would be absurd to suppose that all of these properties are duplicated where the animal and the person coincide. And even if they were duplicated, it would still be hard to explain the alleged difference in persistence conditions. Thus, the Lockean claim that persons are not animals seems hard to justify. The animalist concludes that where I am, there are not two entities that are both living, conscious, thinking and meet the criteria for personhood. There is just one - the animal. This conclusion seems to be in accordance with both common sense and the findings of the natural sciences.

${ }_{6}$ This claim is not accepted by all animalists. Van Inwagen (1990, 170) argues that head transplants preserve biological continuity and, thus, move the animal to the new body. 


\section{The vagueness of composition}

However, the reasoning that the animalist uses to undermine psychological theories seems to lose its footing when we attempt to make sense of the phenomenon of vagueness of composition.

When examined closely, the human organism, or any organism for that matter, resembles a cloud. (Animalists sometimes actually liken a life, the concept they use to define organisms, to a storm.) In a cloud, the sharp boundaries that we observe from a distance become blurry once we inspect it closely. The further we go from the core of the cloud, the more frequently we will find water droplets that are less and less integrated into the body of the cloud, until we find droplets of which it is impossible to say whether they are parts of the cloud or not.

Organisms are very similar. There are particles that are deeply incorporated into their metabolic system, particles that are clearly not and particles that are in various stages of incorporation, making it impossible to determine whether they are parts of the organism or not. These may include, for instance, particles in molecules of food that are being absorbed into the blood stream or particles in dying skin cells. As a result of this indeterminacy of parthood, it is impossible to determine precisely where the boundaries of an organism lie.

The vagueness of composition affects virtually all material objects we encounter every day. But why is it supposed to be a problem, and why should animalists be especially concerned about it? ${ }^{7}$ There is a famous argument, formulated independently by Peter Unger (1980) and Peter Geach (1980), which shows that if we accept the existence of vague boundaries of objects, we are driven to the conclusion that where there seems to be a single object, there are actually a great number of them - something that flies

$7 \quad$ It is not just animalists who should be concerned about vagueness. Adherents to the bodily view, the brain view and even those Lockeans who believe that persons are material entities (see below) should have an account of vagueness. But it has been animalists who have built their opposition to Lockeanism around the idea that positing two numerically distinct but completely overlapping entities leads to a number of problems. Anyone who says that should be especially concerned about vagueness, as I show below. 
in the face of common sense and seems to undermine the animalist's belief that where I am, there is just one material entity that is conscious, intelligent and thinking.

The argument was termed the Problem of the Many by Unger. I will now present a version tailored to my purposes.

1. Suppose there is a human organism with vague boundaries. Call it O.

2. Then there are particles $\mathrm{D}_{1}-\mathrm{D}_{\mathrm{n}}$, which are determinately parts of $\mathrm{O}$, and particles $I_{1}-I_{n}$, which are indeterminately parts of $O$.

3. Then there are various sets of particles $\mathrm{S}_{1}-\mathrm{S}_{\mathrm{n}}$, which are equally suitably arranged to compose ${ }^{8}$ an organism. For instance, $S_{1}=\left\{D_{1}-D_{n}\right\}$, $\mathrm{S}_{2}=\left\{\mathrm{D}_{1}-\mathrm{D}_{\mathrm{n}}, \mathrm{I}_{1}\right\}, \mathrm{S}_{3}=\left\{\mathrm{D}_{1}-\mathrm{D}_{\mathrm{n}}, \mathrm{I}_{2}\right\}$, etc.

4. For each set $\mathrm{S}$, the members of $\mathrm{S}$ compose an entity. (It would be unjustified to claim that the members of $S_{1}$, for instance, compose something, while the members of $\mathrm{S}_{2}$, differing only by a single particle, do not compose anything. The difference of a single particle seems to be compositionally negligible.)

5. If $\mathrm{O}$ exists, then each of these entities is an organism. (It would be unjustified to claim that the members of $S_{1}$ compose an entity which is an organism, while the members of $\mathrm{S}_{2}$, differing only by a single particle, compose an entity which is not an organism. An organism cannot differ from a non-organism by a single particle only.)

6. Then for each organism $\mathrm{O}$, there are a great number of organisms which almost completely overlap O. (Some differ by a single particle, others by more particles, but still negligibly.)

The reason animalists should be concerned about this argument should now be obvious. In their challenge to Lockeanism, animalists show the troublesome implications of Lockeans postulating materially coincident but numerically distinct entities - if a person and an animal coincide, they must share all of their intrinsic properties, they must both think, be intelligent, and

8 Simply put, composition is a relation among objects such that if the objects $\mathrm{O}_{1-}$ $\mathrm{O}_{n}$ stand in that relation, there is an object $\mathrm{P}$ that has objects $\mathrm{O}_{1}-\mathrm{O}_{n}$ as parts. 
be persons. As a result, there are more persons and thinkers than we thought there were. Moreover, only some persist by virtue of psychological continuity. However, if animals are vague objects, the animalist will have to face problems of a very similar type. All the different sets contain particles that have, as far as we can tell, an equal claim to compose an animal, and since they differ so minutely, they will all presumably have virtually the same intrinsic properties. Specifically, if I am conscious, they will almost certainly be conscious, if I am thinking and intelligent, they will almost certainly be thinking and intelligent, and if I am a person, they will almost certainly be persons.

It seems that the animalist is driven to a difficulty quite similar to the one he ascribes to the Lockean. If he has to accept a multiplicity of animals in virtually the same place, why could there not be two material entitiesan animal and a person - in the very same place? Surely, a few particles cannot make that much difference.

\section{Solutions to the Problem of the Many}

Metaphysical theories offer a number of solutions to the Problem of the Many. Peter Unger originally suggested a solution that has become known as nihilism. It is based on the idea that it is absurd to conclude that all of the sets $\mathrm{S}_{1}-\mathrm{S}_{\mathrm{n}}$ contain particles that compose something, and thus denies premise 4 . But the only alternative is that none of the sets compose anything. And if none of them compose anything, there aren't any vague objects. That would not be so troubling if vagueness did not affect all of the objects that we encounter in the world. Since it does, where we thought there were vague objects, there turn out to be only particles that compose nothing. As a result, none of the ordinary things we think there are actually exist (Unger 1980, 462).

This solution is radical and certainly not in tune with what the animalist wants to say. Animalism holds that there is at least one sort of composite object - animals. (Whether there are chairs, clouds or rusty nails is a matter the animalist qua animalist does not attempt to answer.) Nihilism offers too few entities to the animalist.

There are, however, solutions to the problem that the animalist can accept. One solution favoured by two prominent animalists appeals to 
ontic vagueness (van Inwagen 1990, 213-227; Olson 2008, 42). This solution claims that the many organisms are a single organism with vague boundaries. Arguably, the animalist can also accept the brutalist response as defended by Markosian (1998), according to which there is no interesting answer to the question of when composition occurs and compositional facts are brute facts. On this account, particles in only one of the sets compose an organism, but there is no interesting explanation as to why the particles in the other sets do not compose anything. But I want to look more closely at solutions that do not seem to be available to the animalist because they posit far more entities than the animalist is willing to accept. These solutions are, respectively, the semantic account of vagueness (semanticism) based on the notion of supervaluations, and a solution by means of partial identity as defended by David Lewis. At first sight, the animalist cannot treat the vagueness of animals as a matter of semantic indecision, because that solution requires there to be many equally suitable candidates in nearly the same place at the same time. Lewis' analysis of vagueness of composition also entails the existence of a multiplicity of candidates. If correct, these views would seem to be inconsistent with there being just one animal in the space where I am located. $^{9}$

However, both of these solutions are based on the idea that although the multiplicity is real, we can (in a manner of speaking) "cheat" and pretend that there is just one entity in the place where we want it. The key question is whether the animalist can cheat too.

\section{Cheating I}

The semantic solution to the Problem of the Many is based on rejecting premise 5 of the argument. According to that premise, the objects composed by the many sets of particles are all organisms. Semanticism denies thisthe sets of particles do compose entities, but these entities are mere candidates for being an organism, and only one candidate is an organism [see e.g.

$9 \quad$ See, for instance, (Zimmerman 2008, 30). 
(Lewis 1999, 171); ${ }^{10}$ see also (McGee and McLaughlin 2000); (McKinnon 2002)]. Let us look at the details.

Semanticism is a theory according to which vagueness is essentially a linguistic matter resulting from the fact that our expressions do not have precisely specified denotata. According to semanticism, the world is perfectly discrete, containing only entities with sharp boundaries, but our expressions are sometimes indeterminate regarding which of the sharp objects they actually denote. Thus, the expression "tall person" is vague, because it could denote the set of people who are at least $180 \mathrm{~cm}$ tall or the set of people who are at least $190 \mathrm{~cm}$ tall, and we have never needed to determine the denotatum precisely. The vagueness of a term is thus explained by postulating a number of candidate denotata that are precise (so-called "precisifications") and saying that it has not been determined which of the precise candidates is the actual denotatum of the vague term.

But sometimes we could, if we wished to, make a vague term precise by selecting out of the many alternative precisifications the one that will from now on be the denotatum. Sometimes we do just that. For instance, we need to precisify the term "the moment of death" for legal and medical purposes. On other occasions it would be entirely pointless to do so, because what we want to say using the vague term will be true regardless of which of the precisifications is the actual denotatum of the vague term.

But the general assumption of the semantic account is that there are many precisifications for a vague term, each of which is a suitable candidate to be the denotatum of the term. The multiplicity of the candidates seems to be inconsistent with the above argument for animalism and against Lockeanism. Suppose there are a number of candidates to be the organism that I am. Although the candidates do not completely coincide, they overlap so extensively that a great number of them will very likely share many intrinsic properties. Specifically, if I am conscious, many others will be. If I am thinking, many others will be thinking as well. As a result, there would seem to be too many thinkers where we thought there was only

10 Lewis endorses both views to be discussed here - semanticism as well as partial identity. See (Lewis 1999, 179-82). 
one-something the animalist certainly does not want to admit in the light of her argument against Lockeanism.

However, it can be argued that the animalist can accept the semanticist framework if it is enriched by a method known as supervaluation, which assigns truth values to statements containing vague terms [see (Lewis 1999, 171-75)]. In this method, each sentence containing a vague term is broken down into many different interpretations in which the vague term is replaced by one of the precisifications, and the statement is then evaluated. Statements which come out true on every precisification are supertrue. Statements which come out false on every precisification are superfalse. And statements which come out true on some precisifications and false on others are supertruth-valueless. The important lesson is that according to this version of semanticism, the goal of communication is to convey not truth, but supertruth.

Accepting the supervaluationist framework gives us the resources to solve the Problem of the Many in a manner consistent with animalism. More specifically, we can show that it is entirely legitimate to say that where I am, there is just one organism.

To see that, let us focus on a particular organism; call it R. Suppose, then, that there are various precisifications of R. Let us assume for simplicity that there are just four:

$\mathrm{P} 1: \mathrm{R}$ is composed of the set of particles $\mathrm{S}_{1}=\{\mathrm{o}, \mathrm{p}, \mathrm{q}, \mathrm{r}\}$;

P2: $R$ is composed of the set of particles $S_{2}=\{o, p, q, s\}$;

P3: $R$ is composed of the set of particles $S_{3}=\{o, p, r, s\}$;

P4: $R$ is composed of the set of particles $\mathrm{S}_{4}=\{\mathrm{o}, \mathrm{q}, \mathrm{r}, \mathrm{s}\}$.

Suppose that $\mathrm{R}$ is now sitting in the living room and watching TV, and consider the sentence " $\mathrm{R}$ is watching TV".

The supervaluation of this sentence will assign truth values to all of the precisifications of the sentence which result from replacing $R$ with a precisely defined term. For brevity, let us assume that "R(P1)" means "R under the precisification P1".

The following will now hold:

" $\mathrm{R}(\mathrm{P} 1)$ is watching $\mathrm{TV} "$ is true. 
" $\mathrm{R}(\mathrm{P} 2)$ is watching TV" is true.

" $\mathrm{R}(\mathrm{P} 3)$ is watching TV" is true.

" $\mathrm{R}(\mathrm{P} 4)$ is watching TV" is true.

Since the sentence " $\mathrm{R}$ is watching TV" is true on all precisifications, it is supertrue, and we are entitled to assert it.

By contrast, let us now consider the sentence " $R$ is composed of $\{o, p$, $q, r\}$ ". This sentence will be true if $R=R(P 1)$, but it will be false on all other precisifications. This discrepancy in truth values results in the sentence being supertruth-valueless. The same goes for " $R$ is composed of $\{0$, p, q, s\}", etc. Since R is a vague term, we cannot claim that its denotatum is determinately composed of a particular set of particles. Any such claim will lack supertruth value.

But now consider the sentence "Only one set of particles composes R". What will be the supertruth value of this sentence? The above examples suggest that on each precisification only one set of particles composes $\mathrm{R}$. On $\mathrm{R}(\mathrm{P} 1)$ it is $\mathrm{S}_{1}$ and no other set, on $\mathrm{R}(\mathrm{P} 2)$ it is $\mathrm{S}_{2}$ and no other set, etc. Since it is true on every precisification, the sentence "Only one set of particles composes $\mathrm{R}$ " is supertrue and we are justified in asserting it.

The above considerations entail the following claims: $\mathrm{R}$ is a vague term. There are many alternative precisifications of $\mathrm{R}$. It is impossible to say which precisification is the sole legitimate denotatum of $\mathrm{R}$, for none are. However, on any precisification there will be just one $\mathrm{R}$. That means that where I am, there is just one organism, even though it cannot be determinately stated which of the alternative precisifications it is.

Since, according to supervaluationism, the goal of communication is to convey information that is supertrue, and since the sentence "Where I am, there is just one organism" will be supertrue on the supervaluationist account, the animalist is perfectly justified in asserting it.

\section{Cheating II}

The semantic solution to the Problem of the Many is based on rejecting the claim that all of the entities composed by the different sets are organisms. 
Another solution to the Problem of the Many is offered by David Lewis (Lewis 1999, 177-79). Lewis introduces the concept of partial identity to show that although the entities are all organisms, we can still (in a manner of speaking) say that there is just one organism. Because this solution accepts the multiplicity of organisms, it too should be unavailable to the animalist. I will show, however, that this is not necessarily the case.

Let us consider again the entities composed by members of $\mathrm{S}_{1}-\mathrm{S}_{\mathrm{n}}$. In the context of the Lewisian theory, we can admit they are all organisms and call them $\mathrm{O}_{1}-\mathrm{O}_{\mathrm{n}}$. If we interpret the concepts of identity and non-identity in the standard, strict way, $\mathrm{O}_{1}-\mathrm{O}_{\mathrm{n}}$ will all be different from each other. Strict identity is reserved for the relation of an object to itself. Any objects that do not completely overlap are non-identical. And since none of $\mathrm{O}_{1}-\mathrm{O}_{n}$ completely overlap, they are non-identical, that is, different. Lewis, however, suggests a different interpretation, one that is more in tune with common sense and ordinary language. He accepts that the concept of strict identity applies to objects that completely overlap, but reserves the concept of strict non-identity for cases of objects which do not overlap at all, such as my computer and the Eiffel Tower. But in between these two extremes, there is a spectrum of objects that overlap to different degrees, thus falling under the concept of partial identity. At one end there are cases like that of Siamese twins connected only by a finger, and at the other there are objects that share almost every part, such as our organisms $\mathrm{O}_{1}-\mathrm{O}_{\mathrm{n}}$. According to Lewis, objects in this spectrum are partially identical, and objects with very extensive overlap are almost identical (Lewis 1999, 178).

Just as the ordinary notion of identity differs from the concept of strict identity, so does the concept of counting. Strictly speaking, we count according to identity interpreted the standard way. If we do so, the sentence "Where I am, there is just one organism" will be false, because it is not true that $\mathrm{O}_{1}-\mathrm{O}_{n}$ completely overlap. But in ordinary circumstances, says Lewis, we sometimes count according to relations other than identity (Lewis 1999, 175), and there is no reason why we could not use the concept of partial identity for counting, especially in cases where there is very extensive overlap. In such cases we can say the objects are almost identical. As a result, the above sentence will be almost true and by a blameless approximation 
we may say that where I am, there is just one organism. For most contexts, this will be true enough, according to Lewis.

\section{The cheating revealed}

Both the supervaluationist solution and the solution by partial identity enable the animalist to retain the premise of his argument against the psychological theory of personal identity: where I am, there is just one organism (one person, one thinker, etc.). On the supervaluationist solution, although the term "organism $\mathrm{R}$ " is vague and there are a number of precisifications that could be suitable as the denotatum of the term, on any such precisification it will be true that exactly one set contains all and only those particles that compose $\mathrm{R}$. This gives the status of supertruth to the animalist premise. Using partial identity, the animalist may say that although strictly speaking there are many organisms where I am, since they overlap to such a great extent we may say they are almost identical, which is good enough for most contexts.

However, I have already indicated that these two solutions amount to a sort of cheating. Opponents will be quick to point out that the real issue is not what we may permissibly say on most occasions, but what is actually the case. And no matter what we say on these accounts, we still have to face the facts.

The supervaluationist solution fails, its opponents might say, because it merely carefully conceals the fact that the precisifications are all material entities, that they are all extremely similar, and that, as a result, they are all equally well suited to be the organism. The fact that we can speak as if there were just one organism, because nothing turns on which of these entities we pick as the denotatum of the term, cannot hide the simple fact that all these very similar entities exist and that we cannot provide a plausible selection principle for choosing between them. As a result, we must accept the fact that where I am, there are millions of other thinking and intelligent organisms, and I cannot point to a single feature that makes one rather than any other one me.

Similarly, the solution based on partial identity can easily be discredited, because it is simply a form of pretence. Certainly, we can pretend that there 
is just one organism where I am, because all of the organisms that exist there are so extremely similar that we can hardly tell them apart. But this is just a façon de parler. There are all sorts of ways of speaking, but when hard-pressed we would have to admit that even though the organisms are almost identical, they are not in fact identical.

\section{Facing the facts}

Suppose, then, that we admit that we have been cheating, and we face the facts. There are two questions that need to be answered. 1) Do the facts pose any special problems for the animalist as opposed to any reasonable person? 2) Does the admission enable the Lockean to score any points over the animalist? To both of these questions, my answer is no.

Regarding the first problem, we need to remember that the animalist takes the claim "Where I am, there is just one organism" to be a pretheoretical belief, an intuition, that most reasonable people normally accept. It is in all our interests to find a solution to the Problem of the Many, because it challenges this very intuition. The two suggested solutions attempt to save the intuition by saying, in their own ways, that in spite of the actual plurality, the intuition is still, in a sense, correct. If the solutions are deemed unacceptable, then we are all in trouble, for we are all deeply mistaken about how many objects there are. But the animalist, who says that where I am there is just one organism, is not in any deeper trouble than the cabinetmaker who says that she is working on a chest of drawers or the zookeeper who says that she is feeding an elephant. We all want there to be exactly as many things as we believe there are, and the supposition that there are a lot more than we think is disturbing to all of us. To put it another way, the animalist has the same beliefs about the number of animals in the world as ordinary people do. And whatever explication of those beliefs we must accept in order to account for vagueness, the animalist will be happy to accept, too.

But does the admission of plurality of organisms not give the Lockean the right to accept her preferred picture of personal identity? Does it not allow her to claim that where I am, there are two entities, an animal and a person? Could the Lockean not reason as follows? 
If the animalist can accept that where there seems to be one organism, there are, in fact, a great number of them, differing only by a single particle, then the Lockean can accept that where I am, there are two material entities, which do not differ by a single particle. After all, one particle surely cannot make any difference.

Well, it seems that she cannot, because there is a substantial difference between the plurality that the animalist accepts and the plurality that the Lockean defends. Remember that one premise of the Problem of the Many is that all of these alternative objects are so extremely similar that it would be completely unjustified to say one is an organism while the other is not. So they are all organisms. And whatever we normally wish to say about one of them will be true about all of the others. In particular, if one thinks, they all think, and if one has biological persistence conditions, they all do. This is what justifies us cheating, if anything does, and saying there is just one organism, one thinker, one biological continuer, etc.

The Lockean, in contrast, does not want to say that the animal and the person that it shares matter with are such that whatever one says about one of them will also be true of the other, despite the fact that they completely overlap. Some Lockeans say that the animal does not think (Shoemaker 1999), others claim it thinks only derivatively (Baker 2008), but all Lockeans say that the person cannot permanently cease to be conscious, whereas the animal can. So even if we tolerate cheating on the part of the animalist, we still have no justification for tolerating the idea that there can be two completely overlapping numerically distinct objects with different persistence conditions. No solution to the Problem of the Many that is available to the animalist licenses this Lockean claim.

Let's look at the dialectic of the dispute from the perspective of the two mysteries stated above. The animalist claims that the Lockean has to explain the metaphysical and the epistemic mystery. These mysteries arise, it will be remembered, because the Lockean claims that where I am, there are two material entities which completely overlap. Confronted with the vagueness of organisms, the animalist admits that where I am, there are multiple organisms which overlap not completely, but almost completely. Could the Lockean now say that the animalist has to explain the two mysteries, too? 
I don't think so. The metaphysical mystery is a mystery about how two completely overlapping entities might differ in their persistence conditions. But the almost completely overlapping organisms do not differ in their persistence conditions! After all, they are all organisms, and they can all survive whatever an organism can survive. In particular, they can all survive the permanent loss of consciousness. The metaphysical problem is only a problem for the Lockean, because she claims that one of the overlapping entities cannot survive what the other can.

What about the epistemic mystery? Does the animalist not have to explain which of the almost completely overlapping organisms I am? Here the answer is trickier. Notice, however, that the epistemic question is troubling only if the answer has practical consequences. In the Lockean framework, the consequences are important. I need to know whether I am the animal or the person, because the answer entails what I can survive and whether it would be rational for me to visit Alcor, for instance. But in the case of the multiplicity of organisms the answer will have no practical implications, as we have seen. All of the organisms can pretty much survive the same things and get killed by the same things. So even if where I am there are millions of other organisms and I cannot tell which of them I really am, I am still confident that I cannot teleport myself and that developing an autoimmune disease may kill me even if Alcor intervenes at the last minute. So it is a mystery which of these multiple organisms I am, but it is one that is much easier to live (and die) with. ${ }^{11}$ And let's not forget that this is a mystery that most of us have to solve, as we share the animalist intuition about the number of organisms.

Not everyone will be persuaded by this argument. It may be pointed out that I have ignored the real challenge that the problem of the many poses to the animalist and, instead, shifted attention to its practical implications.

11 An anonymous reviewer has pointed out that the epistemic mystery dissolves on the semantic theory of vagueness, because the term 'I' will be vague in much the same way that the term 'organism' is. Thus, there is no answer to the question of which precise object I am, because 'I' does not refer determinately to any of them. I appreciate this comment. 
But the problem is inherently metaphysical and epistemic, and it is in this light that it must be addressed. ${ }^{12}$

Two things can be said in response. First, it may be said that there is some value in purely metaphysical and epistemic arguments, but if nothing in practice turns on these arguments, the value is relatively low. Applying this line of reasoning, which is deeply rooted in the American Pragmatist tradition, we may say that the Lockean position is not disquieting merely because it prevents us from truly knowing whether we are persons or animals, but primarily because such knowledge is necessary for many of our practical interactions. The problem of vagueness of composition that the animalist must face, however, is merely theoretical. Perhaps it is a genuine epistemic issue that I am not able to tell which of the equally well-suited aggregates of matter I am. But nothing else hangs on it. Whether or not I am this or that aggregate of particles, I will be able to do the same things, survive the same changes and have the same mental capacities.

Secondly, the underlying assumption of the presented defence of animalism is the same as that which underlies the whole project of linguistic solutions to vagueness in general. These solutions also emphasize the practical aspects of the issue. The sceptic might object: 'Look, perhaps we can talk as if there were just one cloud in the sky, but the real issue is a metaphysical one, not linguistic - there are many of them and we have no reason for preferring one of them. So, we cannot refer to 'the cloud' and make any statements about it due to referential failure.' But the whole supervaluationist project is based on the idea that the practical issues trump the metaphysical ones. We do succeed in referring to the cloud and saying true things about it in spite of the fact that, metaphysically speaking, there are other equally good candidates. The important thing is that since most of what we say will be true regardless of which candidate is the right one, it might hurt that we cannot solve the metaphysical problem, but not very much.

This brings me to a final point related to the dialectic of the dispute. It has been noted that vagueness affects all composite material objects. The Lockean also believes in such objects. In fact, she believes in more composite

12 I would like to thank another anonymous reviewer for this objection. 
material objects than the animalist, for in her ontology there are persons in addition to animals, and both of these are material and composite. And if animals face the Problem of the Many, surely persons do as well. As a result, the Lockean is bound to believe that where I am, there are millions of almost completely overlapping organisms and millions of almost completely overlapping persons, each of which completely overlaps with one of the organisms, but is not identical to it and differs from it in persistence conditions. The Lockean seems to have a lot more to explain than the animalist. It is not that the Lockean cannot employ supervaluationism or partial identity to account for the vagueness of persons or animals. She surely can. But that is not the main problem the Lockean is facing. The main problem is how to account for their relationship: how to simultaneously maintain that persons are material entities that coincide with animals and that persons and animals are numerically distinct and have different persistence conditions; how to maintain that the animal is distinct from the person when it apparently has the mental properties sufficient for personhood. These are not problems induced by vagueness, so the solutions to the problem of vagueness are of no use there.

\section{Conclusion}

There are currently no generally accepted solutions to the Problem of the Many. Each solution has implications that clash with some of our intuitions. Solutions based on ontic vagueness or on brutal composition entail or are at least consistent with the idea that where I am, there is literally one material object. The solutions I have defended in this paper take a less direct approach, but still enable the animalist at least to say that there is one material object. All of these strategies are respectable, even if they have their critics. My goal has been to show that (a) the animalist is free to adopt the linguistic solutions to the problem, (b) this gives the Lockean no tools for defending her picture of personal identity, and (c) the situation for the Lockean is far more troubling. 


\section{Acknowledgements}

I am indebted to Petr Dvořák for fruitful discussions of vagueness and related issues and to Eric Olson for helpful comments to a draft of this paper.

\section{Funding}

This work was supported by the Czech Science Foundation (GAČR), grant no. 17-12551S.

\section{References}

Baker, Lynne Rudder. 2000. Persons and Bodies: A Constitution View. Cambridge: Cambridge University Press. https://doi.org/10.1017/CBO9781139173124

Baker, Lynne Rudder. 2008. "Response to Eric Olson." Abstracta (special issue I): 43-45.

DeGrazia, David. 2005. Human Identity and Bioethics. Cambridge: Cambridge University Press. https://doi.org/10.1017/CBO9780511614484

deRosset, Louis. 2011. "What is the Grounding Problem?" Philosophical Studies 156 (2): 173-197. https://doi.org/10.1007/s11098-010-9590-4

Geach, Peter T. 1980. Reference and Generality, 3rd edition. Ithaca: Cornell University Press.

Johnston, Mark. 1987. "Human Beings." Journal of Philosophy 84 (2), 59-83. https://doi.org/10.2307/2026626

Johnston, Mark. 2007. "'Human Beings' Revisited: My Body is not an Animal." In Oxford Studies in Metaphysics, vol. 3, edited by Dean Zimmerman, 33-74. Oxford: Oxford University Press.

Lewis, David. 1976. "Survival and Identity." In The Identities of Persons, edited by Amélie Oksenberg Rorty, 17-40. Berkeley: University of California Press.

Lewis, David. 1999. "Many, but Almost One." In Papers in Metaphysics and Epistemology, 164-182. New York: Cambridge University Press. https://doi.org/10.1017/CBO9780511625343.010

Markosian, Ned. 1998. "Brutal Composition." Philosophical Studies 92 (3): 211249. https://doi.org/10.1023/A:1004267523392

McDowell, John. 1997. "Reductionism and the First Person." In Reading Parfit, edited by Jonathan Dancy, 230-250. Oxford: Blackwell.

McGee, Vann, and Brian P. McLaughlin, B. 2000. "The Lessons of the Many." Philosophical Topics 28 (1): 129-151. https://doi.org/10.5840/philtopics200028120 
McKinnon, Neil. 2002. "Supervaluations and the Problem of the Many." Philosophical Quarterly 52 (208): 320-339. https://doi.org/10.1111/1467-9213.00271

Olson, Eric T. 1997. The Human Animal. Personal Identity without Psychology. Oxford, New York: Oxford University Press. https://doi.org/10.1093/0195134230.001.0001

Olson, Eric T. 2007. What Are We? A Study in Personal Ontology. New York: Oxford University Press. https://doi.org/10.1093/acprof:oso/9780195176421.001.0001

Olson, Eric T. 2008. "Replies." Abstracta (special issue I): 32-42.

Olson, Eric T. 2015. "What Does It Mean to Say that We Are Animals?" Journal of Consciousness Studies 22 (11-12): 84-107.

Parfit, Derek. 1984. Reasons and Persons. Oxford: Clarendon Press. https://doi.org/10.1093/019824908X.001.0001

Shoemaker, Sydney. 1984. "Personal Identity: A Materialist's Account." In Personal Identity, edited by Sydney Shoemaker and Richard Swinburne, 67-132. Oxford: Blackwell.

Shoemaker, Sydney. 1999. "Self, Body, and Coincidence." Proceedings of the Aristotelian Society 73 (1): 287-306. https://doi.org/10.1111/1467-8349.00059

Snowdon, Paul F. 2014. Persons, Animals, Ourselves. Oxford: Oxford University Press. https://doi.org/10.1093/acprof:oso/9780198719618.001.0001

Unger, Peter. 1980. "The Problem of the Many." Midwest Studies in Philosophy 5 (1): 411-467. https://doi.org/10.1111/j.1475-4975.1980.tb00416.x

van Inwagen, Peter. 1990. Material Beings. Ithaca: Cornell University Press.

Zimmerman, Dean. 2008. "Problems for Animalism." Abstracta (special issue I): $23-31$. 